\title{
Use of the Box and Block Test for the evaluation of manual dexterity in individuals with central nervous system disorders: A systematic review
}

\author{
Claudia Santos Oliveira', Cibele Santos Almeida', Larissa Carolina Freitas'1, Robéria Santana', Gislene Fernandes', \\ Paulo Roberto Fonseca Junior ${ }^{1}$, Renata Calhes Franco Moura ${ }^{1}$
}

\begin{abstract}
Introduction: Therapies designed to improve the functional capacity of the upper limb have become a vast field of research. Current clinical methods for upper extremity evaluations address function, motor control, sensory deficiency, dexterity, muscle tone and range of motion. The quality and performance in relation to activities related to the work of daily living and recreational activities are largely determined by hand functions and manual dexterity. Abnormal dexterity and the loss of motor coordination are among the main adverse conditions stemming from neurological disorders. Objective: The aim of the present study was to perform a systematic review of the literature on the use of the Box and Block Test (BBT) for the evaluation of manual dexterity in patients with central nervous system disorders. Methods: Searches were performed the Medline, PEDro, Lilacs, Scielo and PubMed databases. The articles retrieved during the initial search were analyzed independently by two blinded reviewers based on the following inclusion criteria: (1) controlled clinical trial; (2) population with neurological disorders; (3) evaluation involving the BBT; (4) outcome: evaluation of manual dexterity; (5) year of publication: 2005 and 2016. Preselected articles were evaluated for methodological quality using the Physiotherapy Evidence Database (PEDro) scale (minimum score for inclusion: 5 points). Results: The search resulted in the retrieval of 51 articles, 42 of which did not meet the inclusion criteria. Nine articles addressed the use of the BBT as one of the methods for the evaluation of manual dexterity in patients with central nervous system disorders, were considered methodologically adequate and were included in the present systematic review. Conclusion: The studies analyzed suggest that the BBT is a fast, easy, safe measure of manual dexterity with good applicability for adults and children with neurofunctional diseases.
\end{abstract}

Key words: Box and Blocks, neurofunctional diseases, manual dexterity

\section{INTRODUCTION}

As an extension of the intellect, the hand is an important creative tool that serves as a means for nonverbal communication and is the most important tactile organ. The hand is capable of performing extremely fine, sensitive movements as well as executing tasks that require considerable strength. Quality and performance regarding work-related activities of daily living and recreational activities are largely determined by functions of the hand and manual dexterity. ${ }^{(1)}$

Poirier et al. ${ }^{(2)}$ relates manual dexterity to learning and training, defining this term as an ability that requires the rapid coordination of voluntary gross and fine movements based on skills developed through learning, training and experience. Dexterity is influenced by age, gender, motor coordination and anthropometric variations. ${ }^{(3-4)}$ Insufficient manual dexterity can exert an impact on the ability to live in an independent fashion, as demonstrated by the close link between impaired dexterity and a reduced capacity regarding the performance of activities of daily living..$^{(5)}$

Abnormal dexterity and the loss of motor coordination are among the main adverse conditions stemming from neurological disorders. ${ }^{(5)}$ Higgis et al. ${ }^{(6)}$ found that the non-rehabilitation of dexterity was devastating to stroke survivors returning to routine activities. Indeed, recovering dexterity means recovering autonomy, even if only partially. The ability to perform small task without assistance makes an individual with a neurological disorder more independent, thereby raising his/her self-esteem and helping the individual make greater efforts throughout the rehabilitation process.

Different therapeutic approaches and techniques have been studied for the rehabilitation of upper limb impairment. Thus, therapies designed to improve the functional capacity of the upper limb have become a vast field of research. ${ }^{(7)}$ Current

Corresponding author: Claudia Santos Oliveira Rua Itapicuru, 380, apto 111 - Barra Funda - São Paulo/ SP - Brasil - CEP: 05006-000 E-mail: csantos@uninove.br

${ }^{1}$ Universidade Nove de Julho (UNINOVE), São Paulo, Brazil

Financial support: The authors gratefully acknowledge financial support from the Brazilian National Council for Scientific and Technological Development (CNPq).

Submission date 10 June 2016; Acceptance date 25 September 2016; Publication online date 15 October 2016 
clinical methods for upper extremity evaluations address function, motor control, sensory deficiency, dexterity, muscle tone and range of motion. ${ }^{\left({ }^{8}\right)}$ The diverse functions of the upper extremity and the innumerous possibilities of hand movements have led to a large number of standardized scales and objective evaluation methods for measuring upper extremity movements. ${ }^{(9-10)}$ The choice of an adequate assessment tool should be based on factors such as psychometric properties, time required to manage the interpretation of the results, cost, the need for specific equipment, the need for experience and portability. ${ }^{(11)}$ The literature offers a large number of dexterity tests, which are frequently employed in occupational therapy to measure and monitor changes in motor impairment as well as measure the degree of patient recovery with regard to the potential to return to work. ${ }^{(12-13)}$

The Box and Block Test (BBT) developed and validated by Mathiowet $z^{(14-15)}$ was designed as an evaluation method to test individuals with manual dysfunction. The aim is to evaluate and measure dexterity as well as the functions of grasping, holding and throwing. ${ }^{(16)}$ The evaluation is performed with the individual seated in front of a box with a large divider separating it into two equal squares. ${ }^{(17)}$ The volunteer is instructed to transport small wooden blocks from one side to the other for one minute. ${ }^{(18-6)}$ Following three trials performed with each hand, the number of blocks is recorded for the right and left hands separately. ${ }^{(10)}$ The BBT is considered a fast, simple, reliable test that is often used for older adults and stroke survivors. ${ }^{(19)}$ Moreover, high degrees of inter-rater $(r>0.9)$ and test-retest $(r>0.9)$ reliability are reported for both the right and left hands. ${ }^{(15)}$ The BBT was brought to Brazil by the Neurology Group of the São Paulo Santa Casa de Misericórdia for use on individuals with multiple sclerosis. ${ }^{(20)}$

Studies have employed the BBT as a sensitive tool for measuring dexterity in patients with neurological disorders. (21-23) However, methodological reflections regarding its applicability are fundamental to the use of this test not only to stratify participants in clinical trials, but also to evaluate the results of therapy and the effectiveness of rehabilitation protocols $^{(24)}$ in complement to the different functional scales used for the evaluation of upper extremity function.

The aim of the present study was to perform a systematic review of the literature on the use of the Box and Block Test for the evaluation of dexterity in patients with neurological disorders.

\section{METHODS}

\section{IDENTIFICATION AND SELECTION OF STUDIES}

The Pubmed, Medline, Lilacs, Scielo and PEDro databases were searched for relevant articles published in English and Portuguese between January 2005 and June 2016. The following key words were used in both languages: "Box and
Blocks AND Neurofunctional disease", "Box and Blocks AND manual dexterity".

\section{INCLUSION CRITERIA}

The articles retrieved during the initial search were analyzed independently by two blinded reviewers based on the following inclusion criteria: 1) controlled clinical trial; 2) population with neurological disorders; 3) evaluation and intervention for disorders of the central nervous system; 4 ) evaluation involving the BBT; and 5) evaluation of manual dexterity as the outcome.

\section{METHODOLOGICAL QUALITY}

The methodological quality of the preselected articles was evaluated using the Physiotherapy Evidence Database (PEDro) scale, which has 11 items, each of which is scored with either 1 point or zero (except for Item 1, which is not scored). Thus, the final score ranges from 0 to 10 points. The scale is used to evaluate the methodological quality of randomized, controlled, clinical trials, placing emphasis on whether the results have sufficient information, clinical relevance and statistical significance so that the interpretation is clear and other researchers can reproduce the study. All divergences of opinion between the two reviewers with regard to the PEDro classification were discussed until reaching a consensus on the score attributed to each study.

\section{RESULTS}

The initial search of the databases led to the retrieval of 51 articles (Fig. 1). Following the analysis of the titles, abstracts and full texts, pre-selected articles were submitted to qualitative analysis using the PEDro for the inclusion of only those studies with a score of 5 points or more (Table 1 ). Nine articles met the inclusion criteria and were selected for the present systematic review (see Table 2 and Table 3).

\section{DISCUSSION}

Motor and sensory tasks performed by the hand allow adequate functioning with regard to activities of daily living. Dysfunction of the hand exerts a direct impact on independence. Thus, the aim of many forms of treatment is to reduce the deficiency in the belief that this will lead to greater manual dexterity and functional capacity.

The clinical trials analyzed in the present systematic review employed a diversity of methods and treatments to improve performance during functional activities. This diversity in treatment options is also reported in a previous systematic review conducted by Sakzewski et al. ${ }^{(32)}$, who stress the absence of strong evidence regarding a specific therapeutic model for improving upper extremity movements in cases of hemiparesis secondary to cerebral palsy.

A systematic review and metanalysis conducted by Sakzewski et al. ${ }^{(33)}$ reported an increase in publications with the 


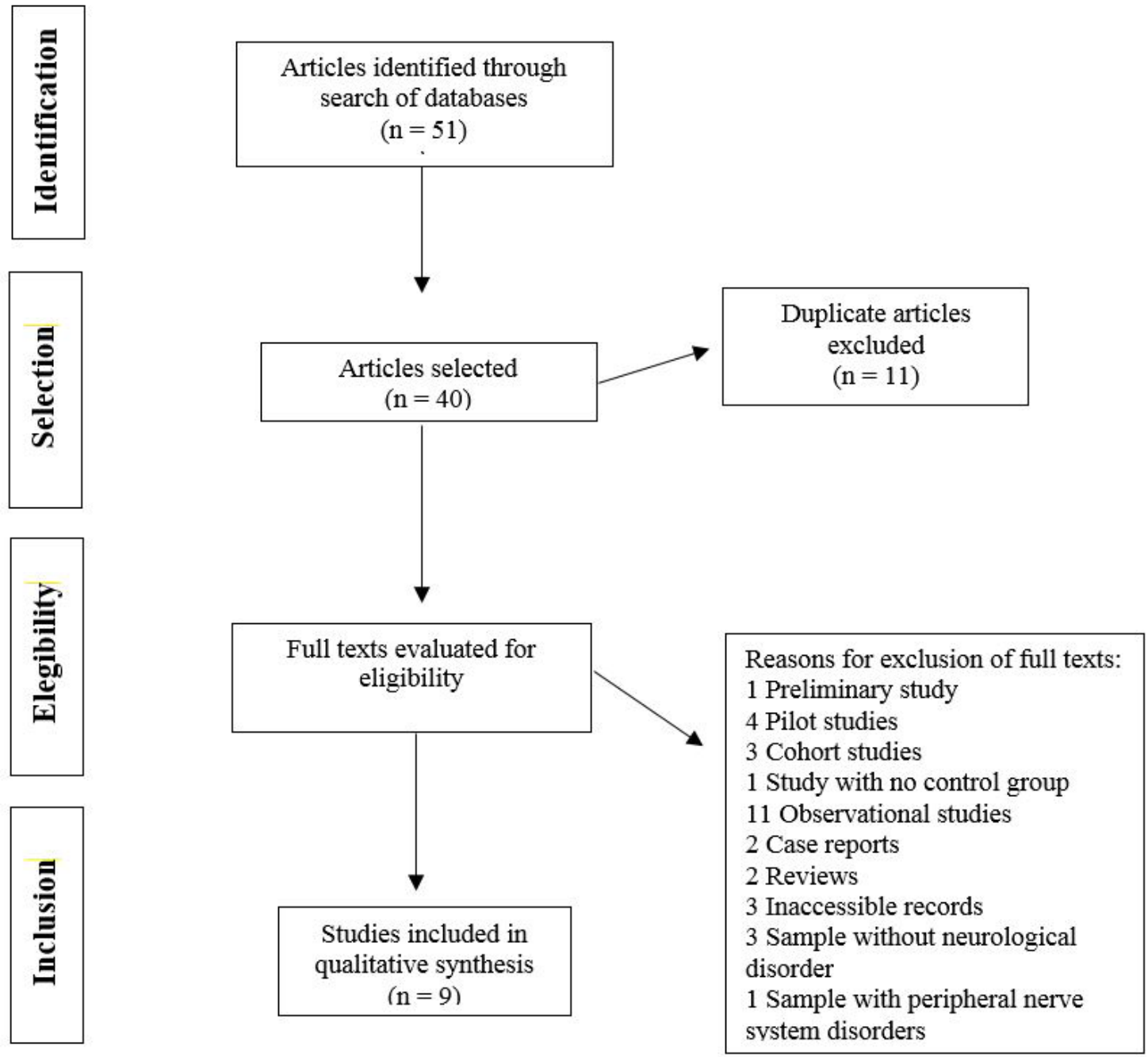

Figure 1. Flowchart of study selection process.

Table 1. Methodological quality scores (PEDro scale) of articles included in systematic review.

\begin{tabular}{|c|c|c|c|c|c|c|c|c|c|c|c|c|}
\hline \multirow[b]{2}{*}{ Reference } & \multicolumn{11}{|c|}{ Item } & \multirow[b]{2}{*}{ ๖ัّ } \\
\hline & 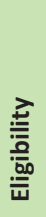 & 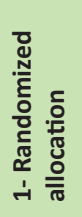 & 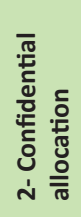 & 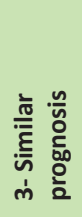 &  & 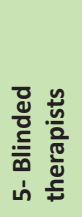 & 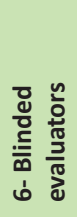 & 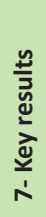 & 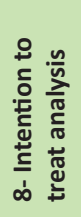 & 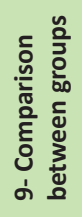 & 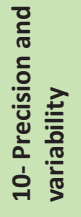 & \\
\hline Higgins, J. et al. $(2006)^{19}$ & 1 & 1 & 1 & 1 & 0 & 0 & 1 & 1 & 1 & 1 & 1 & $8 / 10$ \\
\hline James H. Cauraugh., et al. $(2011)^{25}$ & 0 & 1 & 1 & 1 & 0 & 0 & 1 & 0 & 0 & 1 & 1 & $6 / 10$ \\
\hline Marco Franceschini., et al. $(2012)^{26}$ & 1 & 1 & 1 & 1 & 0 & 0 & 1 & 0 & 0 & 1 & 1 & $6 / 10$ \\
\hline Sin, HH, Lee, GC. $(2013)^{27}$ & 1 & 1 & 0 & 1 & 0 & 0 & 1 & 1 & 0 & 1 & 1 & $6 / 10$ \\
\hline Stefano Masiero., et al. $(2013)^{28}$ & 1 & 1 & 0 & 1 & 0 & 0 & 1 & 0 & 1 & 1 & 1 & $6 / 10$ \\
\hline Yvonne Geerdink., et al. $(2013)^{7}$ & 0 & 1 & 0 & 1 & 0 & 0 & 0 & 1 & 1 & 1 & 1 & $6 / 10$ \\
\hline Hyun Jin Kim, et al. (2014) & 1 & 1 & 1 & 1 & 0 & 0 & 1 & 1 & 0 & 1 & 1 & $7 / 10$ \\
\hline Keh-chung Lin. et al. $(2014)^{31}$ & 1 & 1 & 1 & 1 & 0 & 0 & 1 & 1 & 0 & 1 & 1 & $7 / 10$ \\
\hline Gilliaux, M. et al. $(2015)^{30}$ & 1 & 1 & 1 & 1 & 0 & 0 & 1 & 1 & 1 & 1 & 1 & $8 / 10$ \\
\hline
\end{tabular}


Table 2. Characteristics of articles included in systematic review

\begin{tabular}{|c|c|c|c|c|c|}
\hline AUTHORS & $\begin{array}{c}\text { № OF } \\
\text { SUBJECTS }\end{array}$ & POPULATION & DESCRIPTION OF GROUPS & INTERVENTION & EVALUATION MEASURES \\
\hline $\begin{array}{l}\text { Higgins et al. } \\
\qquad(2006)^{19}\end{array}$ & $\mathrm{n}=91$ & Stroke & $\begin{array}{l}\text { EG } 47 \text { individuals } \\
\text { CG: } 44 \text { individuals }\end{array}$ & $\begin{array}{l}\text { - EG: Arm training } \\
\text { - CG: Mobility training }\end{array}$ & $\begin{array}{l}\text { - Box and Block Test } \\
\text { - Nine-Hole Peg Test } \\
\text { - Grip strength } \\
\text { - The upper extremity subscale } \\
\text { of Stroke Rehabilitation } \\
\text { Assessment of Movement } \\
\text { - Barthel Index } \\
\text { - Older Americans Resources } \\
\text { and Services Scale - } \\
\text { Instrumental Activities of } \\
\text { Daily Living } \\
\text { - Medical Outcomes Study } \\
\text { 36-Item Short Form } \\
\text { Questionnaire (SF-36) } \\
\text { - Geriatric Depression Scale }\end{array}$ \\
\hline $\begin{array}{l}\text { Cauraugh et al. } \\
(2011)^{25}\end{array}$ & $\mathrm{n}=18$ & Stroke & $\begin{array}{l}\text { - ST-EG: } 7 \text { individuals in short- } \\
\text { term (ST) therapy } \\
\text { - LT-EG: } 11 \text { individuals in long- } \\
\text { term (LT) therapy } \\
\text { - CG: } 7 \text { individual without } \\
\text { brain injury }\end{array}$ & $\begin{array}{l}\text { Protocol: Bilateral arm movements } \\
+ \text { active stimulation of affected arm; } \\
6 \text { hours of duration for period of } 22 \\
\text { days } \\
\text { - ST-EG } 1 \text { protocol } \\
\text { - LT-EG: } 10 \text { protocols }\end{array}$ & $\begin{array}{l}\text { - Box and Blocks test } \\
\text { - Fractionated reaction times } \\
\text { - Production of sustained force }\end{array}$ \\
\hline $\begin{array}{l}\text { Franceschini et al. } \\
\qquad(2012)^{26}\end{array}$ & $\mathrm{n}=102$ & Stroke & $\begin{array}{l}\text { EG: } 49 \text { individuals } \\
\text { CG: } 53 \text { individuals }\end{array}$ & $\begin{array}{l}\text { EG: Watched videos of daily tasks } \\
\text { performed with upper extremity } \\
\text { to imitate action presented } \\
\text { - CG: Viewed } 5 \text { images of upper } \\
\text { extremity actions to imitate action } \\
\text { presented, simulating treatment } \\
\text { in EG }\end{array}$ & $\begin{array}{l}\text { - Fugl-Meyer Scale } \\
\text { - Frenchay Arm Test } \\
\text { - Box and Block Test } \\
\text { - Modified Ashworth Scale } \\
\text { - Functional Independence } \\
\text { Measure }\end{array}$ \\
\hline $\begin{array}{l}\text { Sin HH et al. } \\
(2013)^{27}\end{array}$ & $\mathrm{n}=40$ & Stroke & $\begin{array}{l}\text { EG: } 18 \text { individuals } \\
\text { CG: } 178 \text { individuals }\end{array}$ & $\begin{array}{l}\text { EG : Virtual reality training using } \\
\text { Xbox Kinect and conventional } \\
\text { occupational therapy } \\
\text { CG: Conventional occupational } \\
\text { therapy alone }\end{array}$ & $\begin{array}{l}\text { - Active range of motion of } \\
\text { upper extremity } \\
\text { - Fugl-Meyer Assessment } \\
\text { - Box and Block Test }\end{array}$ \\
\hline $\begin{array}{c}\text { Masiero et al. } \\
(2013)^{28}\end{array}$ & $\mathrm{n}=34$ & Stroke & $\begin{array}{l}\text { EG: } 16 \text { individuals } \\
\text { CG: } 18 \text { individuals }\end{array}$ & $\begin{array}{l}\text { EG: Standard therapy ( } 65 \% \text { of } \\
\text { training time) + robotic training } \\
\text { ( } 35 \% \text { of training time) } \\
\text { CG: Conventional upper extremity } \\
\text { therapy }\end{array}$ & $\begin{array}{l}\text { - Modified Ashworth Scale } \\
\text { - Medical Research Council } \\
\text { - Fugl-Meyer Test } \\
\text { - Box and Block Test } \\
\text { - Frenchay Arm Test } \\
\text { - Functional Independence } \\
\text { Measure }\end{array}$ \\
\hline $\begin{array}{l}\text { Geerdink et al. } \\
(2013)^{7}\end{array}$ & $\mathrm{n}=50$ & $\begin{array}{l}\text { Hemiplegic } \\
\text { cerebral palsy }\end{array}$ & $\begin{array}{l}\text { EG: } 28 \text { children } \\
\text { CG: } 22 \text { children }\end{array}$ & $\begin{array}{l}\text { EG: Modified constraint-induced } \\
\text { movement therapy for } 6 \text { weeks, } \\
\text { tested weekly with Box and } \\
\text { Block Test to evaluate changes } \\
\text { in manual dexterity during } \\
\text { intervention } \\
\text { - CG: Bimanual therapy for } 8 \text { weeks } \\
\text { (72 h) }\end{array}$ & $\begin{array}{l}\text { - Assisting Hand Assessment, } \\
\text { ABILHAND-Kids and } \\
\text { Secondary } \\
\text { - Melbourne } \\
\text { - COPM } \\
\text { - Box and block test }\end{array}$ \\
\hline $\begin{array}{l}\text { Kim et al. } \\
(2014)^{29}\end{array}$ & $\mathrm{n}=27$ & Stroke & $\begin{array}{l}\text { EG: } 14 \text { individuals } \\
\text { GC: } 13 \text { individuals }\end{array}$ & $\begin{array}{l}\text { EG: Functional electrical } \\
\text { stimulation (FES) with mirror } \\
\text { therapy + conventional training } \\
\text { - CG: Sham FES with mirror therapy } \\
\text { + conventional training }\end{array}$ & $\begin{array}{l}\text { - } \text { COPM } \\
\text { - Box and block Test } \\
\text { - Strength assessment scale }\end{array}$ \\
\hline
\end{tabular}

\footnotetext{
of Disability Inventory; MT: mirror training; MG: mesh glove afferent stimulation.
} 
Table 2. Continued...

\begin{tabular}{|c|c|c|c|c|c|}
\hline AUTHORS & $\begin{array}{c}\text { № OF } \\
\text { SUBJECTS }\end{array}$ & POPULATION & DESCRIPTION OF GROUPS & INTERVENTION & EVALUATION MEASURES \\
\hline $\begin{array}{l}\text { Keh-chung Lin et al } \\
(2014)^{31}\end{array}$ & $n=43$ & Stroke & $\begin{array}{l}\text { MT: } 14 \text { patients } \\
\text { MG: } 14 \text { patients } \\
\text { CG: } 15 \text { patients }\end{array}$ & $\begin{array}{l}\text { All participants received one training } \\
\text { session } 1.5 \text { hours per day five days a } \\
\text { week for four weeks. } \\
\text { - MT protocol: } 10 \text { minutes of warm- } \\
\text { up, } 1 \text { hour of mirror box training } \\
\text { and } 20 \text { minutes of functional task } \\
\text { practice } \\
\text { - MG protocol was similar to MT } \\
\text { group, but group also wore MG } \\
\text { during mirror box training. } \\
\text { - CG : } 10 \text { minutes of warm-up and } \\
\text { 1h } 20 \text { minutes of task-oriented } \\
\text { treatment principles. }\end{array}$ & $\begin{array}{l}\text { - Fugl-Meyer Assessment } \\
\text { - Muscle tone measured } \\
\text { by Myoton-3 for motor } \\
\text { impairment } \\
\text { - Box and Block Test } \\
\text { - } 10-\text {-Meter Walk Test } \\
\text { - Kinematic parameters for } \\
\text { motor control } \\
\text { - Motor activity } \\
\text { - Questionnaire for daily } \\
\text { function }\end{array}$ \\
\hline $\begin{array}{l}\text { Gilliaux et al. } \\
(2015)^{30}\end{array}$ & $\mathrm{n}=16$ & $\begin{array}{l}\text { Cerebral } \\
\text { palsy }\end{array}$ & $\begin{array}{l}\text { EG: } 8 \text { children } \\
\text { CG: } 8 \text { children }\end{array}$ & $\begin{array}{l}\text { Both groups received five } 45 \text {-minute } \\
\text { sessions for eight weeks } \\
\text { - CG - } 5 \text { sessions of conventional } \\
\text { therapy } \\
\text { - EG - } 3 \text { sessions of conventional } \\
\text { therapy and } 2 \text { sessions of robot- } \\
\text { assisted therapy }\end{array}$ & $\begin{array}{l}\text { - Free Amplitude Task } \\
\text { - Box and Block Test } \\
\text { - QUEST } \\
\text { - Modified Ashworth Scale } \\
\text { - Muscle strength of elbow } \\
\text { flexors and extensors } \\
\text { (dynamometer) } \\
\text { - Abilhand-Kids } \\
\text { - PEDI }\end{array}$ \\
\hline
\end{tabular}

Legend: CG: control group; EG: experimental group; COPM: Canadian Occupational Performance Measure; QUEST: Quality of Upper Extremity Skills Test; PEDI: Pediatric Evaluation of Disability Inventory; MT: mirror training; MG: mesh glove afferent stimulation.

Table 3. Results of articles included in systematic review.

\section{AUTHORS}

Higgins et al. (2006)

Cauraugh et al. (2011) ${ }^{25}$

Franceschini et al. (2012)

Sin HH et al. (2013) ${ }^{27}$

Masiero et al. (2013)

Geerdink et al. (2013)

Kim et al. (2014)

Keh-chung Lin et al $(2014)^{31}$

Gilliaux et al. (2015) ${ }^{30}$

\section{RESULTS}

- On affected arm, performance on BBT was approximately $40 \%$ of predicted score for age. During post-intervention evaluation, a mean of 28 blocks (standard deviation: 17 blocks) and 28 blocks (standard deviation: 19 blocks) were found for the experimental and control groups, respectively. No significant change was found in arm function measures.

- Group submitted to long-term treatment demonstrated significant improvements: (a) more blocks transferred (43 vs. 32), (b) faster pre-motor reaction time (158 v. $208 \mathrm{~ms}$ ) and (c) greater force production (75 vs. $45 \mathrm{~N}$ )

- Long-term improvement in all measures evaluated for both treatment protocols; time $\times$ treatment interaction based on generalized estimation equations for BBT, demonstrating significant differences favoring experimental group

- After intervention, significant improvements from baseline values in range of motion of upper extremity, Fugl-Meyer Assessment scores and Box and Block Test scores found in experimental and control groups. At follow-up, significant differences between two groups in range of motion (except for wrist), Fugl-Meyer Assessment score, and Box and Block Test scores .

- When used as partial replacement of traditional rehabilitation therapy, robotic therapy is at least as effective as conventional therapy for treatment of stroke survivors with hemiparesis in acute phase of disease, capable of providing relatively similar gains on function and motor scales - results could be considered lack of efficacy of proposed device

- Fifteen children $(53.6 \%)$ demonstrated maximum effect within period of modified constraint-induced movement therapy. Children less than five years of age had greater chance of reaching maximum score within six weeks of modified constraint-induced movement therapy $(\mathrm{OR}=6.67,95 \% \mathrm{Cl}: 1.24-35.71)$. Older children demonstrated greater progression, but tended to decline afterward. Findings suggest that children aged five years or more can benefit more from long-term constraint-induced movement therapy and one-hand training has direct influence on capacity for two-hand development.

- On evaluation scale, scores for shoulders, arms, wrists and hands as well as upper extremity coordination increased significantly following intervention in both groups. Both groups demonstrated significant improvements in all variables after intervention.

- Total scores were significantly higher and synergistic shoulder abduction during reach was lower in MT+ MG and MT groups in comparison to control group. Performance on BBT and 10-meter walk test (velocity and stride length in selfpaced task and velocity in as-quickly-as-possible task) was better in MT + MG group in comparison to MT group

- Improvement in manual dexterity of upper extremity in experimental group, with increase in final Box and Block Test score. Capacity to perform analytical movements and score of dissociated movements on Quality of Upper Extremity Skills Test subscale increased significantly in both groups. 
aim of upper extremity rehabilitation involving contemporary approaches based on motor learning. However, the review raised questions regarding the duration of the intervention, as the exact critical threshold regarding the dose of intervention necessary to achieve significant changes in upper extremity function remains unknown, which was also found among the studies analyzed in the present review.

Cauraugh ${ }^{(25)}$ et al. conducted a study with stroke survivors in the chronic phase of the disease submitted to 60 hours of different upper extremity rehabilitation protocols distributed throughout the course of 16 months. Greater improvements in motor capacity were found in individuals submitted to long-term therapy in comparison to those submitted to short-term therapy, such as 1) a greater number of blocks transferred during the BBT, 2) faster reactions a greater number of times and 3) greater force production. The results led to the identification of the benefits of continual learning (long-term therapy) to the progression of motor recovery. According to Franceshini et al., ${ }^{(26)}$ the evaluation of time versus treatment interaction based on an analysis of the performance of experimental and control groups suggests that the BBT assists considerably in the analysis of manual dexterity in stroke survivors as well as the monitoring of the results of rehabilitation procedures.

Evaluation scales are used in rehabilitation to provide a basis for diagnoses and prognoses as well as the determination of the response to treatment. Such objective scales assist in measuring the degree of motor impairment with regard to sensory-motor functions and functional capacity and serve as a complement to the subjective evaluation of self-reports. (23) A variety of assessment tools is used to describe upper extremity function in individuals with typical and atypical development. ${ }^{(22,34)}$ However, this diversity poses a challenge and it is important for researchers to understand that the choice of measures depends of the objectives of a given study. ${ }^{(34)}$

In the present systematic review, the different assessment tools were employed for the quantification of the results of different therapeutic protocols. The BBT was used for the evaluation of manual dexterity, with no reports of any difficulty in the use of the test among the randomized controlled trials analyzed, demonstrating that this test can be used for both adults and children with neurological disorders. However, age plays a factor when using the BBT on the pediatric population. Investigating the progression of dexterity in children with unilateral spastic cerebral palsy aged two to eight years, Geerdink et al. ${ }^{(7)}$ found that children older than five years of age transferred 2.3-fold more blocks than those less than five years of age. This may be explained by the greater cognitive phase of motor learning among older children, whereas younger children are in a more associative phase.

Masiero et al. ${ }^{(28)}$ found that robot-assisted therapy combined with a traditional rehabilitation protocol is at least as effective as conventional therapy alone for the treatment of hemiparesis among stroke survivors in the acute phase of the disease, as this technique is capable of producing relatively similar results with regard to the functional and motor scales evaluated. In a study involving robot-assisted therapy, Gilliaux et al. ${ }^{\left({ }^{30}\right)}$ included the use of the BBT for the evaluation of body structure and hand function. The interaction between treatment time and group revealed that smooth, discrete, unidirectional movements improved in the experimental group, demonstrating an improvement in dexterity in the affected hand.

Kim et al. ${ }^{(29)}$ analyzed the effect of functional electrical stimulation with mirror therapy on motor function in the affected upper extremity of stroke survivors and found that both the experimental and control groups exhibited significant improvements with regard to all variables. Although muscle contraction due to electrical stimulation may improve voluntary movements, the effects on functional capacity are small. Thus, physical training combined with a cognitive intervention is considered necessary to improving motor performance.

In the study by Higgins et al., ${ }^{(6)}$ a reduction in the results of the BBT was found between the pre-intervention and post-intervention analyses, with no significant changes in the statistical data. The authors state that multiple linear regression analysis is needed, with the BBT as the outcome and age, gender, depression, dominant side, previous stroke event, number of comorbidities and type of stroke as the predictors for the identification and adjustment of prognostic variables to improve the precision of estimates of the effect of arm training on a change in the BBT score due to the interaction between depressive symptoms and treatment group. The size effect was calculated by dividing the mean difference of the change in score between the experimental and control groups by the standard deviation of the initial score of the control group.

Keh-chung Lin et al. ${ }^{(31)}$ used the BBT to evaluate manual dexterity and found large, significant effects on motor function. The authors also found an improvement in dexterity with all types of treatment analyzed. Employing additional training involving virtual reality with the $\mathrm{Xbox} \mathrm{Kinect}^{\mathrm{TM}}$, Sin and Lee ${ }^{(27)}$ found an improvement in dexterity in both the experimental and control groups, as evaluated using the BBT, with significant differences in the follow-up evaluation. However, the effects of virtual reality training with this product required a longer overall intervention time in comparison to the control group.

In the studies included in the present systematic review, considerable variations were found with regard to age, level of ability, type of intervention and evaluation methods. The findings demonstrate that evaluation methods should be selected in a discerning manner to ensure greater precision with regard to the results, independently of the aim of the study and target population. However, the studies analyzed suggest that that the Box and Block Test is a fast, easy, safe 
measure of manual dexterity with good applicability for both adults and children with neurofunctional diseases.

\section{ACKNOWLEDGMENTS}

The authors gratefully acknowledge financial support from the following Brazilian fostering agencies: National Council for Scientific and Technological Development (CNPq) and Coordination for the Evaluation and Improvement of Higher Education Personnel (CAPES).

\section{AUTHOR'S CONTRIBUTION}

Oliveira, C.S.: Responsible for the structure of the article and final review. Almeida, C.S.: Responsible for pEDRO scale score and structure of the article. Freitas, L.C.: Responsible for the data-based search. Santana, R.: Responsible for the data-based search and structure of the article. Fernandes, G.: Responsible for the data-based search. Fonseca Junior, P.R.: Responsible for pEDRO scale score. Moura, R.C.F.: Responsible for the structure of the article, pEDRO scale score and final review.

\section{CONFLICTS OF INTEREST}

The author(s) declare that they have no competing interests.

\section{REFERENCES}

1. Carmeli E, Patish H, Coleman R. The Aging Hand. J. Gerontol. Med. Sci. 2003;58a(2):146-152.

2. Poirier F. Dexterity as a valid measure of hand function: 23. A pilot study. Occup. Ther. Health Care 1988;4(3-4):69-83.

3. Gable C, Xenard J, Makiela E, Chau N. Evaluation fonctionnelle de la main. Bilan des 400 points et tests chiffrés. Ann Réad Méd Phys 1997;40:95-101.

4. Kalron A, Greenberg-Abrahami M, Gelav S, Achiron A. Effects of a new sensory reeducation training tool on hand sensibility and manual dexterity in people with multiple sclerosis. NeuroRehabilitation 2013;32:943-948

5. Falconer J, Hughes SL, Naughton BJ, Singer R, Chang RW, Sinacore JM. Self report and performance-based hand function tests as correlates of dependency in the elderly. J Am Geriatr Soc 1991;39:695-699.

6. Higgins J, Salbach NM, Wood-Dauphinee S, Richards CL, Côté R, Mayo NE. The effect of a task-oriented intervention on arm function in people with stroke: a randomized controlled trial. Clin Rehabil 2006;20:296-310

7. Geerdink Y, Aarts $P$, Geurts A. Motor learning curve and long-term effectiveness of modified constraint-induced movement therapy in children with unilateral cerebral palsy: a randomized controlled trial. Res. Dev. Disabil. 2013;34:923-931.

8. Krumlinde-Sundholm L1, Holmefur M, Kottorp A, Eliasson AC. The assisting hand assessment: current evidence of validity, reliability, and responsiveness to change. Dev Med Child Neurol 2007;49:259-264.

9. Moura RCF, Almeida CS, Dumont AJL, Lazzari RD, Lopes JBP, Duarte NAC, et al. Kinematic upper limb evaluation of children and adolescents with cerebral palsy: a systematic review of the literature. J Phys Ther Sci. 2016 Feb;28(2):695-700.

10. Santos CA, Moura RCF, Lazzari RD, Dumont AJ, Braun LA, Oliveira CS. Upper limb function evaluation scales for individuals whith cerebral palsy: a systematic review. J Phys Ther Sci. 2015 May;27(5):1617-20.

11. Tyson S, Connell L. The psychometric properties and clinical utility of measures of walking and mobility in neurological conditions: a systematic review. Clin Rehabil 2009;23:1018-1033.

12. Desrosiers J, Rochette A, Hébert R, Bravo G. The Minnesota manual dexterity test: reliability, validity and reference values studies with healthy elderly people. Can. J. Occup. Ther., 1997;64(5):270-276.

13. Desrosiers J, Bravo G, Hébert R, Dutil E, Mercier L. Validation of the box and block test as a measure of dexterity of elderly people: reliability, validity, and norms studies. Arch. Phys. Med. Rehabil., 1994;75(7):751-755.
14. Mathiowetz V, Federman S, Wiemer D. Box And Block Test Of Wan AI Dex, Norms For 6-19 Year Olds. Cjot 1985;52(5):241-245

15. Mathiowetz V, Volland G, Kashman N, Weber K. Adult norms for the box and block test of manual dexterity. Am. J. Occup. Ther. 1985;39(6):386391.

16. Arnould C, Penta M, Renders A, Thonnard JL. Abilhand-Kids: a measure of manual ability in children with cerebral palsy. Neurology, 2004;63:10451052.

17. Page SJ, Levin L, Hermann V, Dunning K, Levine P. Longer versus shorter daily durations of electrical stimulation during task-specific practice in moderately impaired stroke. Arch Phys Med Rehabil, 2012;93:200-206.

18. Priosti P, Assis S, Cymrot R, Vianna DL, Caromano FA. Força de preensão e destreza manual na criança com síndrome de Down. Fisioter Pesq. 2013;20(3):278-285

19. Mendes MF, Tilbery CP, Balsimelli S, Moreira MA, Cruz AMB. Teste de destreza manual da caixa e blocos em indivíduos normais e em pacientes com esclerose múltipla. Arq. Neuro-Psiquiatr. 2001;59(4):889-894.

20. Nunes CMP, Cavalcante A, Galvão CR. Avaliação e técnicas de avaliação nas áreas de desempenho ocupacional. Terapia Ocupacional, Fundamentação E Prática. Rio De Janeiro: Guanabara Koogan, 2007.

21. Guimarães R, Blascovi-Assis S. Uso do Teste Caixa e Blocos na avaliação de destreza manual em crianças e jovens com síndrome de Down. Rev. Ter. Ocup. Univ. São Paulo, 2012;23(1):98-106.

22. McCarthy M, Silberstein CE, Atkins EA, Harryman SE, Sponseller PD, Miller NAH. Comparing reability and validity of pediatric instruments for measuring health and well-being of children with spastic cerebral palsy. Developmental Medicine \& Child Neurology. 2002;44,468-476.

23. Cavaco NS, Alouche SR. Instrumentos de avaliação da função de membros superiores após acidente vascular encefálico: uma revisão sistemática. Fisioterapia e Pesquisa. 2010;17(2):178-83.

24. Thompson-Butel AG, Lin GG, Shiner CT, McNulty PA. Two Common Tests of Dexterity Can Stratify Upper Limb Motor Function After Stroke. Neurorehabilitation and Neural Repair 2014;28(8):788-796.

25. Cauraugh JH, Naik S, Lodha N, Coombes SA, Summers JJ. Long-Term rehabilitation for chronic stroke arm movements: a randomized controlled trial. Clin. Rehabil. 2011;25(12):1086 - 1096.

26. Franceschini $M$, Ceravolo $M$, Agosti $M$, Cavallini $P$, Bonassi $S$, Dall'Armi $\mathrm{V}$, et al. Clinical relevance of action observation in upper-limb stroke rehabilitation: a possible role in recovery of functional dexterity. A randomized clinical trial. Neurorehabil Neural Repair, 2012;26:456.

27. Sin $\mathrm{HH}$, Lee GC. Additional. Virtual Reality Training Using Xbox kinect in stroke survivors with hemiplegia. Am.J. Phys. Med. Rehabil. 2013;92(10):871-80.

28. Masiero S, Armani M, Ferlini G, Rosati G, Rossi A. Randomized trial of a robotic assistive device for the upper extremity during early inpatient stroke rehabilitation. Neurorehabil. Neural. Repair, 2013;28(4):377-386.

29. Kim H, Lee $G$, Song C. Effect of functional electrical stimulation with mirror therapy on upper extremity motor function in poststroke patients. J Stroke Cerebrovasc Dis. 2014;23(4):655-661.

30. Gilliaux M, Renders A, Dispa D, Holvoet D, Sapin J, Dehez B, et al. Upper Limb Robot-Assisted therapy in cerebral palsy: a single-blind randomized controlled trial. Neurorehabilitation and Neural Repair 2015;29(2)-183192.

31. Keh-Chung Lin, Pai-Chuan Huang, Yu-Ting Chen Wu CY, Huang WL. Combining afferent stimulation and mirror therapy for rehabilitating motor functions after stroke. Neurorehabilitation and Neural Repair 2014;28(2)-153-162.

32. Sakzewski L, Ziviani J, Boyd R. Systematic review and meta-analysis of therapeutic management of upper limb dysfunction in children with congenital hemiplegia. Pediatrics 2009;123:E1111-E1122.

33. Sakzewski L, Ziviani J, Boyd R. Efficacy of upper limb therapies for unilateral cerebral palsy: A meta-analysis. Pediatrics 2014;133(1):e175-e204.

34. Sposito MMM, Riberto M. Avaliação da funcionalidade da criança com paralisia cerebral espastica. Acta Fisiatrica. 2010;17(2):50-61. 